Int. J. Electrochem. Sci., 15 (2020) $1996-2012$

\title{
Study on the Effect of $\mathrm{F}^{-}$and $\mathrm{Cl}^{-}$on the Differentiation of $904 \mathrm{~L}$ Stainless Steel Passive Film in acid Environment
}

\author{
Xiaoqing Feng ${ }^{1,2}$, Wei Shi ${ }^{1,2}$, Xuhong Chen ${ }^{3}$, and Song Xiang ${ }^{1,2, *}$ \\ ${ }^{1}$ College of Materials and Metallurgy, Guizhou University, Guiyang 550025, China; \\ ${ }^{2}$ Key Laboratory for Mechanical Behavior and Microstructure of Materials of Guizhou Province, \\ Guizhou University, Guiyang 550025, China \\ ${ }^{3}$ Institute of Metrology and quality Inspection of Chongqing, Chongqing 401123, China; \\ "E-mail: sxiang@gzu.edu.cn
}

doi: $10.20964 / 2020.03 .01$

Received: 5 October 2019 / Accepted: 3 December 2019 / Published: 10 February 2020

In the field of metal corrosion, understanding the corrosive mechanism of corrosive ions on metals is very important for the protection of materials. In this paper, the effect of $\mathrm{F}^{-}$and $\mathrm{Cl}^{-}$on the corrosion of 904L stainless steel surface passive film in an acidic environment was studied. A comparison was made between how two ions form and destroy the passive film on a $904 \mathrm{~L}$ stainless steel surface. Electrochemical dynamic behavior was studied by using cyclic polarization, potentiostatic polarization, electrochemical impedance spectroscopy (EIS), and so on. Selective solubilization was studied by an inductively coupled plasma optical emission spectrometer (ICP-OES) and the constitution of surface product films was analyzed by X-ray photoelectron spectroscopy (XPS). The results show that the $\mathrm{F}^{-}$ participate in the composition of the passive film formed by $904 \mathrm{~L}$ in the $\mathrm{F}^{-}$-containing acidic environment.

Keywords: 904L stainless steel; cyclic polarization; passive film; $\mathrm{F}^{-} ; \mathrm{Cl}^{-}$

\section{$\underline{\text { FULL TEXT }}$}

(C) 2020 The Authors. Published by ESG (www.electrochemsci.org). This article is an open access article distributed under the terms and conditions of the Creative Commons Attribution license (http://creativecommons.org/licenses/by/4.0/). 